\title{
RUANG KOMUNAL BARU: PERANCANGAN FASILITAS KOMUNITAS (REKREASI- RELAKSASI-KEBUGARAN) DENGAN PENDEKATAN ARSITEKTUR BIOFILIK DI PLUIT, JAKARTA UTARA
}

\author{
Arnantya Fajar Ramadhanti ${ }^{1)}$, Suryono Herlambang ${ }^{2)}$
}

1)Program Studi S1 Arsitektur, Fakultas Teknik, Universitas Tarumanagara, arnantyafajarr@gmail.com

2) Program Studi S1 PWK, Fakultas Teknik, Universitas Tarumanagara, suryonoh@ft.untar.ac.id

Masuk: 04-07-2021, revisi: 14-08-2021, diterima untuk diterbitkan: 23-10-2021

\begin{abstract}
Abstrak
Kota saat ini menjadi tempat tinggal yang dipilih bagi separuh populasi manusia. Kota sendiri termasuk bagian dari ekologi yang di dalamnya terdapat berbagai sistem. Alasan mengapa penduduk memilih untuk tinggal di kota adalah karena banyak fasilitas pendukung dan peluang untuk berkembang. Namun, hal tersebut tidak menjamin manusia selalu bahagia, akan banyak masalah terjadi seiring perubahan masa dan waktu sehingga dapat menyebabkan pemicu stress. Apalagi sejak terjadinya pandemi yang berdampak pada masyarakat diharuskan bekerja maupun bersekolah dari rumah. Tinggal di kota dengan tempat tinggal yang saling berhimpitan, kurangnya lahan terbuka, seperti apartemen maupun perumahan akan membuat masyarakat merasakan ruang semakin terbatas. Berdasarkan hal tersebut, diperlukan ruang yang dapat menurunkan tekanan stress. Tujuannya adalah membuat ruang komunal baru sebagai tempat berinteraksi membentuk komunitas untuk saling memberikan dukungan sosial dengan desain yang ramah terhadap lingkungan, salah satunya dengan menerapkan desain biofilik. Penerapan biofilik dapat berpengaruh membantu manusia meningkatkan kualitas hidup dalam hal psikologis dan memiliki ciri khas yang menggabungkan pola alam ke bangunan sehingga dapat mengurangi stress. Ruang komunal baru ini dapat digunakan oleh masyarakat terutama yang tinggal di sekitar tapak dengan program utama memberikan fasilitas ruang publik yang mudah dijangkau. Fasilitas tersebut antara lain untuk bekerja dan belajar, tempat konsultasi psikologis pada pihak profesional, berkomunitas seperti berkebun, memasak, workshop, maupun fasilitas rekreasi seperti jogging, berenang, salon, bioskop.
\end{abstract}

Kata kunci: biofilik; komunitas; kota; stress; wellness

\begin{abstract}
Cities are now the preferred place of residence for half the human population. The city itself is part of the ecology in which there are various systems. The reason residents choose to live in the city is the many supporting facilities and opportunities for growth. However, this does not guarantee that humans are always happy, there will be many problems that occur as time and time change so that it can cause stress triggers. Especially since the pandemic has impacted people, they are required to work or attend school from home. Living in a city with overlapping residences, the lack of open lands, such as apartments or housing, will make people feel that space is increasingly limited. Based on this, we need a space that can reduce stress. The goal is to create a new communal space as a place to interact to form a community to provide social support to each other with environmentally friendly designs, one of which is by applying biophilic designs. The application of biophilic can help humans improve the quality of life in terms of psychology and has a characteristic that combines natural patterns into buildings to reduce stress. The community can use this new communal space, especially those living around the site, with the main program providing easy-toreach public space facilities. These facilities include work and study, a place for psychological consultations with professionals, communities such as gardening, cooking, workshops, as well as recreational facilities such as jogging, swimming, salon, cinema.
\end{abstract}

Keywords: biophilic; city; community; stress; wellness 


\section{PENDAHULUAN}

\section{Latar Belakang}

Dunia saat ini bergeser menuju ke perkotaan. Kota juga salah satu contoh bagian dari ekologi yang di dalamnya terdapat berbagai sistem kompleksitas buatan dan sebagian besar didominasi oleh manusia (Harsiti, 1992). Dalam survey diketahui jika separuh populasi global memilih menetap dan merantau ke kota. Perserikatan Bangsa-Bangsa (PBB) menyatakan jika jumlah populasi tersebut diperkirakan terus meningkat mencapai angka 68\% pada tahun 2050 (The Mental Health Improvement For Stress-Free Environment, n.d.). Mengapa hal demikian terjadi? Menurut pendapat ahli, hidup di kota tinggi tantangan sosial dan perekonominya termasuk dalam hal pendapatan dibandingkan dengan di desa. Masyarakat di kota selalu dituntut untuk bersaing. Alasan terbesar pindah ke kota karena fasilitas dan peluang yang besar untuk berkembang. Namun, tinggal di kota tidak selalu membuat manusia bahagia, terkadang kualitas hidup di kota tidak sesuai realita kebutuhan. Banyak masalah akan hadir seiring meningkatnya intensitas aktivitas.

Namun, adanya pandemi di awal tahun 2020 menyebabkan aktivitas lingkungan mengalami perubahan, ada dampak positif dan negatif yang ditimbulkan. Kemacetan Jakarta berkurang karena setiap pekerja dan pelajar melakukan work from home sehingga polusi oleh kendaraan bermotor berkurang. Tetapi, kebijakan untuk tetap tinggal di rumah, membatasi bepergian, dan berkumpul di keramaian ini menjadikan penyebab baru dari stress. Berdasarkan isu tersebut, rencana proyek yang diusung adalah tempat yang dapat menurunkan tekanan stress.

Visi dari proyek ini adalah sebagai wadah wellness community (community center) yang menghadirkan pengalaman komunitas menyenangkan sebagai tempat interaksi sosial dalam kehidupan bertetangga untuk dapat menurunkan tingkat stress terhadap kehidupan sehari-hari dan dengan adanya pandemi saat ini. Lalu beberapa misi yang dicapai, yaitu sebagai berikut :

a. Memberikan fasilitas pelayanan seputar kesehatan, ruang untuk bekerja, dan hiburan

b. Menciptakan fasilitas yang menerapkan bangunan sustainable dengan menggunakan teknologi yang ramah lingkungan dan terbarukan guna mendukung keadaan yang terjadi di sekitar tapak perencanaan dan tentunya untuk turut menjaga alam dari dampak negatif.

Manfaat dari proyek ini diharapkan dapat bermanfaat di dalam sebuah komunitas agar dapat merasakan healing yang berfokus pada keluarga dan neighborhood yang dapat saling berinteraksi agar orang tetap berada di lingkungan kawasan tempatnya tinggal, namun dapat tetap pergi untuk berekreasi dan relaksasi, tetapi tidak bertemu dengan orang luar terlalu intens.

\section{Urgensi Isu}

Berdasarkan latar belakang, maka urgensi isu yang diangkat dari adalah sebagai berikut :

a. Aktivitas lingkungan berubah akibat pandemi yang menyebabkan aktivitas semakin terbatas.

b. Dibutuhkannya ruang publik sebagai tempat pelepas penat, kebosanan, dan stress.

\section{Rumusan Permasalahan}

Berdasarkan identifikasi masalah, maka rumusan masalah adalah sebagai berikut :

a. Dapatkah arsitektur membantu proses dalam menurunkan tingkat stress perkotaan?

b. Program arsitektur apa yang dapat menjadi wadah kebutuhan masyarakat sebagai pereda stress?

\section{Batasan Masalah}

Berdasarkan pemaparan yang telah disampaikan di atas, batasan masalah ditentukan sebagai berikut :
a. Isu
: Permasalahan kesehatan psikologis manusia oleh faktor eksternal, yaitu stress.
b. User
: Sasaran pengguna pada proyek ini adalah semua kalangan usia masyarakat.
c. Lokasi
: Kota Jakarta pada lokasi tapak dengan kriteria tertentu. 


\section{Tujuan}

Tujuan dari desain ini adalah sebagai berikut :

a. Menghadirkan program yang memfasilitasi kebutuhan well-being pada komunitas masyarakat.

b. Menyediakan fasilitas rekreasi, relaksasi, dan kebugaran sebagai ruang publik.

c. Menyediakan ruang terbuka hijau sebagai alternatif penghilang stress sekaligus dapat sebagai penghijauan di kota.

d. Membantu menurunkan tingkat stress dengan menyediakan tempat "healing".

\section{KAJIAN LITERATUR}

\section{Ekologi Dalam Arsitektur}

Ekologi pada mulanya berasal dari Bahasa Yunani (gabungan kata oikos+logos), merujuk pada awalan kata "eco" lalu mengacu pada oikos yang artinya rumah, tempat tinggal, habitat, dan dengan perluasannya adalah lingkungan, lalu logos berarti ilmu. Istilah ekologi pertama kali diperkenalkan oleh seorang ahli biologi di Jerman tahun 1866, Ernst Haeckel (Antonioli, 2017). Lalu apa ekologi itu sendiri? Ekologi berarti cabang ilmu hubungan interaksi organisme hidup dengan benda mati (misalnya iklim, tanah, dan lainnya) dan makhluk hidup di lingkungan itu sendiri yang kemudian berkembang menjadi ilmu yang mempelajari struktur fungsi ekosistem sehingga dapat menganalisis memberi jawaban terhadap berbagai kejadian yang terjadi di alam (Hernández, 2010). Sementara ekosistem, yaitu kompleks dinamis komunitas tumbuhan, hewan, mikroorganisme, serta lingkungan tak hidup yang berinteraksi satu kesatuan fungsional, manusia juga termasuk bagian dari ekosistem (Ecosystems \& Well-Being, 2003).

Ekologi arsitektur menciptakan pembangunan ramah lingkungan dan hemat energi dalam mengelola sumber daya alam secara efektif. Gerakan ini memerlukan secara pasif dan aktif memanfaatkan energi matahari dan menggunakan bahan yang sebisa mungkin dalam pembuatannya, aplikasi, dan pembuangan mengandung zero waste.

\section{Prinsip Ekologi Dalam Arsitektur}

a. Memahami konteks

b. Berhubungan dengan alam

c. Memahami proses alami

d. Memahami dampak lingkungan

e. Memahami manusia (Hernández, 2010).

\section{Wellness Community}

Merupakan sekelompok orang yang tinggal dalam jarak dekat untuk berbagi tujuan, minat, dan pengalaman yang sama dalam mengejar kesehatan secara pro-aktif di berbagai bidangnya. Dengan prinsip dari "saya" menjadi "kita", menciptakan kesadaran bahwa kesehatan dan kesejahteraan individu kita sangat terkait dengan lingkungan serta orang di sekitar kita. Komunitas ini merupakan kombinasi kondisi sosial, ekonomi, lingkungan, budaya, dan politik yang diidentifikasi oleh individu dan komunitasnya sebagai hal yang penting bagi mereka untuk berkembang dan memenuhi potensi mereka (What Is Wellness Lifestyle Real Estate \& Communities? - Global Wellness Institute, n.d.).

Dalam sistem perawatan kesehatan saat ini, peran wellness community menjadi semakin penting. Dengan didasarkan pada pendekatan kesehatan masyarakat dengan dua asumsi. Pertama, kebanyakan penyakit dapat dicegah, termasuk berbagai jenis penyakit mental. Kedua, komunitas itu sendiri memiliki banyak solusi untuk kebutuhan kesehatannya sendiri dan sudah memiliki banyak teknik untuk mendorong ketahanan dan kebugaran (What Is Wellness Lifestyle Real Estate \& Communities? - Global Wellness Institute, n.d.).

Selain itu konsep kesehatan sering kali hanya berfokus pada kesehatan fisik dan mental saja, salah satunya melalui olahraga untuk menjalani hidup yang sehat. Namun, terdapat tujuh 
dimensi utama kebugaran lainnya yang berkontribusi pada kesehatan dan kualitas hidup secara keseluruhan. Ke tujuh dimensi kesehatan tersebut antara lain adalah: kesehatan fisik, kesehatan emosional, kesehatan intelektual, kesehatan spiritual, kesehatan lingkungan, kesehatan sosial, dan kesehatan kerja (The 7 Dimensions of Wellness / Mindbody, n.d.).

\section{Stress Dalam Kehidupan Sehari-hari}

Stress termasuk reaksi normal pada seseorang terhadap situasi tertentu yang terjadi di sekitarnya sebagai tantangan atau ancaman dari keberadaannya. Jenis stress bisa berasal dari kecelakaan, penyakit/kesehatan, psikologis, masalah keuangan, masalah dalam pekerjaan atau dengan keluarga, melalui emosi dan reaksi fisik terhadap situasi maupun lingkungan tertentu. Beberapa jenis stress tidak dapat dipisahkan satu sama lain, jika satu pemicu stress terjadi maka menyebabkan pemicu lainnya. Dari semua jenis ini, tingkat stress bisa ringan sampai ekstrim. Stress bukanlah diagnosis, tetapi memang proses yang terjadi seiring waktu.

Istilah lain, seperti kekhawatiran, kecemasan, ketakutan, ketidaksabaran, dan kemarahan digantikan dengan kata stress ini atau lebih tepatnya cabang dari stress. Tingkat dan luasnya stress yang dirasakan seseorang tergantung pada sikapnya menghadapi situasi tertentu. Stress tidak selalu merupakan hal buruk karena beberapa orang berkembang pesat dan bahkan membutuhkannya sebelum dapat menyelesaikan sesuatu. Istilah "stress" jika digunakan dalam arti klinis, mengacu pada situasi yang menyebabkan ketidaknyamanan dan kesusahan bagi seseorang (Stewart, 1975).

\section{Tahapan Dalam Stress}

Menanggapi sebuah fenomena stress, tahapan yang dapat dialami adalah sebagai berikut:

a. Tahap 1: Alarm Stage (Menganggap keadaan lingkungan sebagai ancaman).

b. Tahap 2: Resistance (Upaya menghadapi, memperbaiki kerusakan oleh stressor).

c. Tahap 3: Exhaustion (Tubuh dan pikiran tidak mampu memperbaiki sehingga terjadi burnout) (General Adaptation Syndrome: Your Body's Response to Stress, n.d.).

\section{Community Stress}

\section{Perlunya Menangani Community Stress}

Fenomena pandemi merupakan tantangan terkait kesehatan mengingat protokol untuk mengontrol penyebaran virus, arahan bagi penyedia jasa kesehatan sebagai lini terdepan, penutupan bisnis, dan jarak sosial yang sangat dibatasi, layanan sosial, dan kegiatan ekonomi yang mengarah ke sebuah peningkatan stress. Stress merupakan respon normal, tetapi berdampak negatif terhadap kesehatan mental dan fisik termasuk kecemasan, depresi, penggunaan zat dan PTSD, terutama saat stressor dan durasi tidak pasti, seperti dengan bencana alam, pencemaran lingkungan, dan arus pandemi. Ketahanan dalam komunitas mengacu pada kemampuan adaptasi, meningkatkan kesehatan, dan pulih dari kondisi yang mengancam.

Mengembangkan strategi respon terkoordinasi untuk ketahanan stress dalam komunitas akan membantu mengurangi risiko, penurunan morbiditas, dan mortalitas terkait stress, serta mengidentifikasi dan meningkatkan sumber daya untuk respon lokal, daerah, dan nasional. Bagaimana organisasi memilih menangani komunitas stress karena pandemi akan bergantung pada kebutuhan, sumber daya, dan kapasitas kesehatan masyarakat (Contamination \& Resiliency, n.d.)

\section{Soft City and Slowness}

Jan Gehl berkomitmen untuk membuat kota, lingkungan, dan tempat di mana orang memiliki kendali atas kesehatan dan kesejahteraan mereka sendiri dan sadar akan iklim dalam kehidupan sehari-hari. Jan Gehl juga terinspirasi dari kota asalnya di mana warga 52\% bersepeda untuk pergi melakukan aktivitas, hal itu tidak hanya meningkatkan kesehatan, tetapi mengurangi jejak karbon. 
Tantangan dalam Soft City and Slowness diantaranya saat kota semakin padat dan biaya lahan untuk perumahan semakin melonjak sehingga memaksa banyak orang untuk menghuni sebuah ruang yang lebih kecil (apartment), menyeimbangkan privasi dan sosialisasi menjadi lebih sulit, depresi dan kesepian, lalu sebuah epidemi kesehatan terjadi yang mengharuskan orang tinggal di dalam ruangan terus menerus, duduk di dalam bangunan berventilasi dengan cahaya, berkendara dengan mobil kemana pun. Jadi, kota adalah tentang bergerak dan berinteraksi lebih dekat untuk berkumpul, menghubungkan satu orang ke orang lainnya dan untuk semua aspek kehidupan di sekitar mereka.

Soft City and Slowness memberikan beberapa aspek dasar bentuk perkotaan yang berkelanjutan, membentuk komunitas yang tangguh, dan kehidupan yang sehat bersama orang yang tinggal di dalamnya untuk mengakomodasi kepadatan dan keragaman kehidupan seharihari dengan cara memberikan kenyamanan, keramahtamahan, dan komunitas. Manfaat lain dari Soft City and Slowness adalah membangun dan memiliki identitas bersama dengan komunitas yang berasal dan berbagi tempat maupun sumber daya yang sama (Sim, 2019).

\section{METODE}

Penelitian diperoleh dari metode pengumpulan data melalui studi kasus dan studi literatur yang berasal dari buku maupun internet. Tahap mendesain proyek dimulai dari pemahaman tema, pencarian isu,literatur, maupun studi kasus proyek serupa, pemilihan lokasi, analisis data, menentukan metode maupun strategi, lalu penyusunan konsep rancangan untuk hasil akhir.

Analisis data penelitian dilakukan dengan membandingkan data yang telah didapat dengan teori pendukung. Beberapa analisis yang dijabarkan diantaranya, analisis tapak, analisis program, dan analisis metode yang digunakan. Penyusunan konsep menggunakan beberapa strategi dari hasil analisis tersebut kemudian digabungkan menjadi dengan metode biofilik.

\section{Biophilic Design}

Bio memiliki arti, yaitu "hidup atau makhluk hidup", sementara philia artinya "cinta". Biophilic sendiri berarti cinta untuk hidup atau kecintaan manusia terhadap alam secara naluriah. Kata biophilic pertama kali digunakan oleh Erich Fromm tahun 1964 untuk menggambarkan orientasi psikologis ketertarikan terhadap semua yang hidup. Tidak seperti fobia atau ketakutan yang dimiliki orang terhadap benda-benda di alam, philia adalah daya tarik dan perasaan positif yang dimiliki orang terhadap habitat tertentu, aktivitas, dan objek di lingkungan alaminya (Heerwagen, 2009).

Biophilia telah menjadi kebutuhan bawaan langsung dengan alam yang menjadi penting bagi kesehatan fisik, mental, produktivitas, dan kesejahteraan diri manusia. Memenuhi kebutuhan kontak dengan alam di lingkungan alami ke dalam tempat kita tinggal adalah sesuatu hal yang dapat disebut dengan biophilic design. Kebutuhan biologis kita untuk berhubungan dengan alam ini menjadi penting bahkan di kota yang semakin berkembang. Kemajuan desain berkelanjutan dapat memperbaiki situasi lingkungan, namun sebagian hanya berfokus untuk mengurangi kerusakan lingkungan dari limbah dan polusi atau penggunaan sumber daya yang berlebihan seperti energi dan air. Biofilik menciptakan lingkungan bagi komunitas untuk memenuhi kebutuhan yang berhubungan dengan alam (Dias, 2015).

\section{Prinsip Desain Biofilik}

a. Membutuhkan keterlibatan berkelanjutan dengan alam.

b. Berfokus untuk kepentingan memajukan kesehatan, kebugaran, dan kesejahteraan.

c. Mendorong keterikatan emosional pada pengaturan dan tempat tertentu.

d. Mendorong interaksi positif manusia dan alam

e. Mendorong arsitektur saling menguatkan, berhubungan, dan terintegrasi menghasilkan solusi. 


\section{Manfaat Desain Biofilik}

a. Sebagai desain yang restoratif untuk memulihkan diri

b. Sebagai ekologi sosial dari stress

c. Turut mempromosikan "wellbeing" (Menurunkan stress, rasa marah, dan kelelahan)

d. Membawa alam ke dalam desain (Tanaman, green wall, taman, dan cahaya alami)

e. Pengalaman langsung dari elemen alam (Burnett, n.d.)

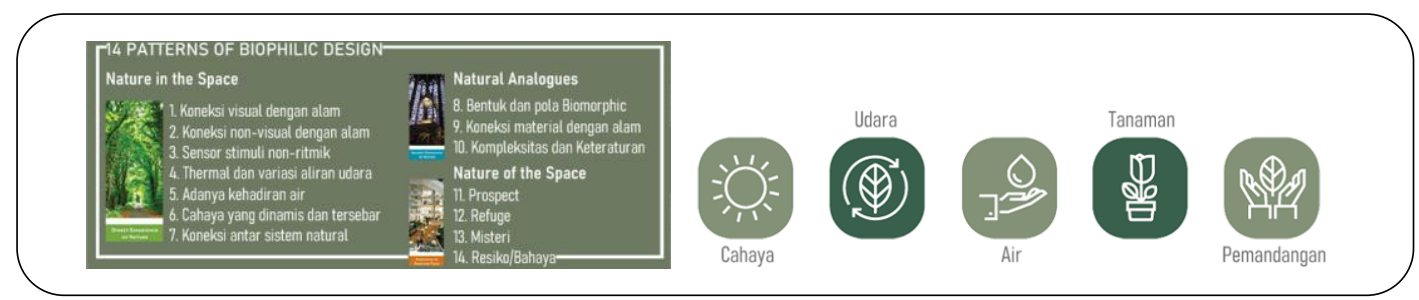

Gambar 1. Pola dan Elemen Desain Biofilik

Sumber: The Practice of Biophilic Design, Stephen R. Kellert, Elizabeth F. Calabrese, 2015

\section{DISKUSI DAN HASIL PERANCANGAN}

\section{Analisis Tapak}

\section{Analisis Makro}

Pemilihan berdasarkan survey terhadap tingkat stress. Jakarta berada di urutan ke enam dengan tingkat stress tertinggi di Asia. Pemilihan lingkup lebih kecil lagi berdasarkan kriteria seperti, berada di sekitar hunian terutama apartemen kelas menengah dan perumahan, lokasi jauh dari bising, akses mudah dicapai, dan site ada unsur alami seperti pohon, air, dan lainnya.

\section{Analisis Messo}

Analisis messo berada di Kawasan Pluit, Penjaringan, Jakarta Utara.

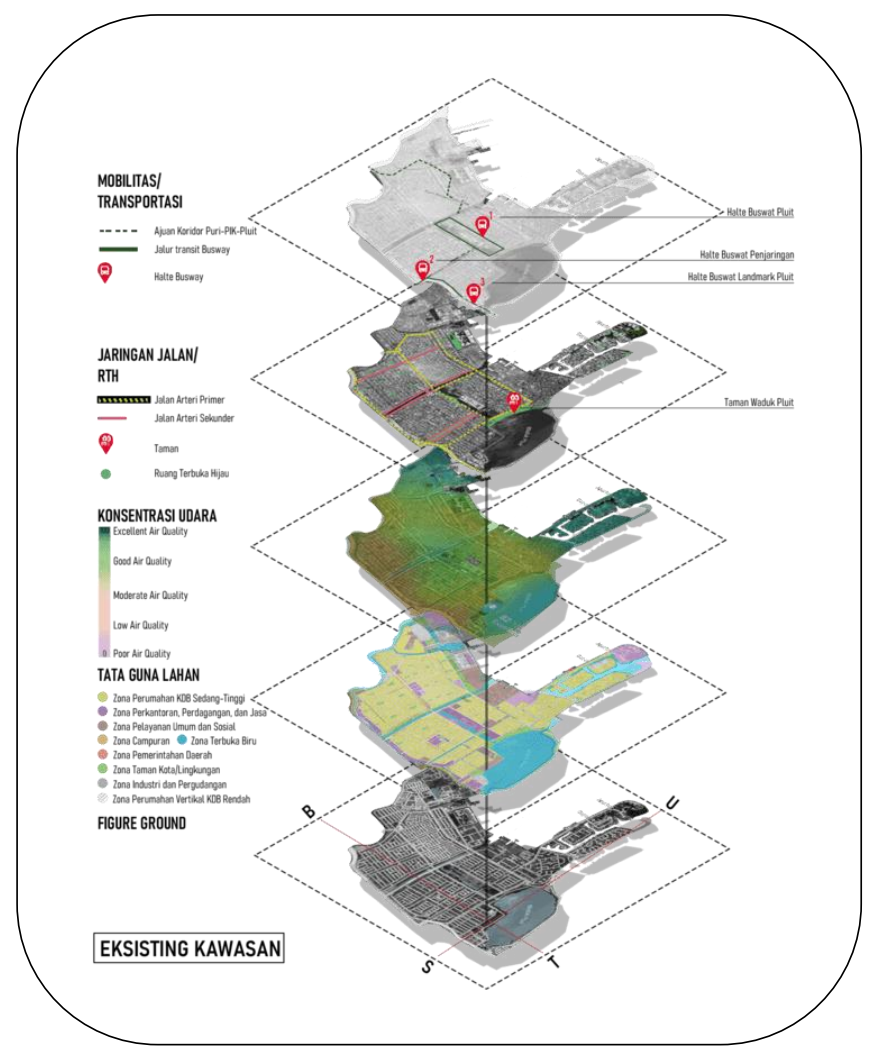

Gambar 2. Analisis Messo

Sumber: Penulis, 2021 


\section{Analisis Mikro}

Tapak berbentuk persegi panjang dengan sisi terpanjang mengarah ke arah utara dan selatan dengan luas total mencapai $\pm 32.665,80 \mathrm{~m}^{2}$. Tapak merupakan lahan kosong.

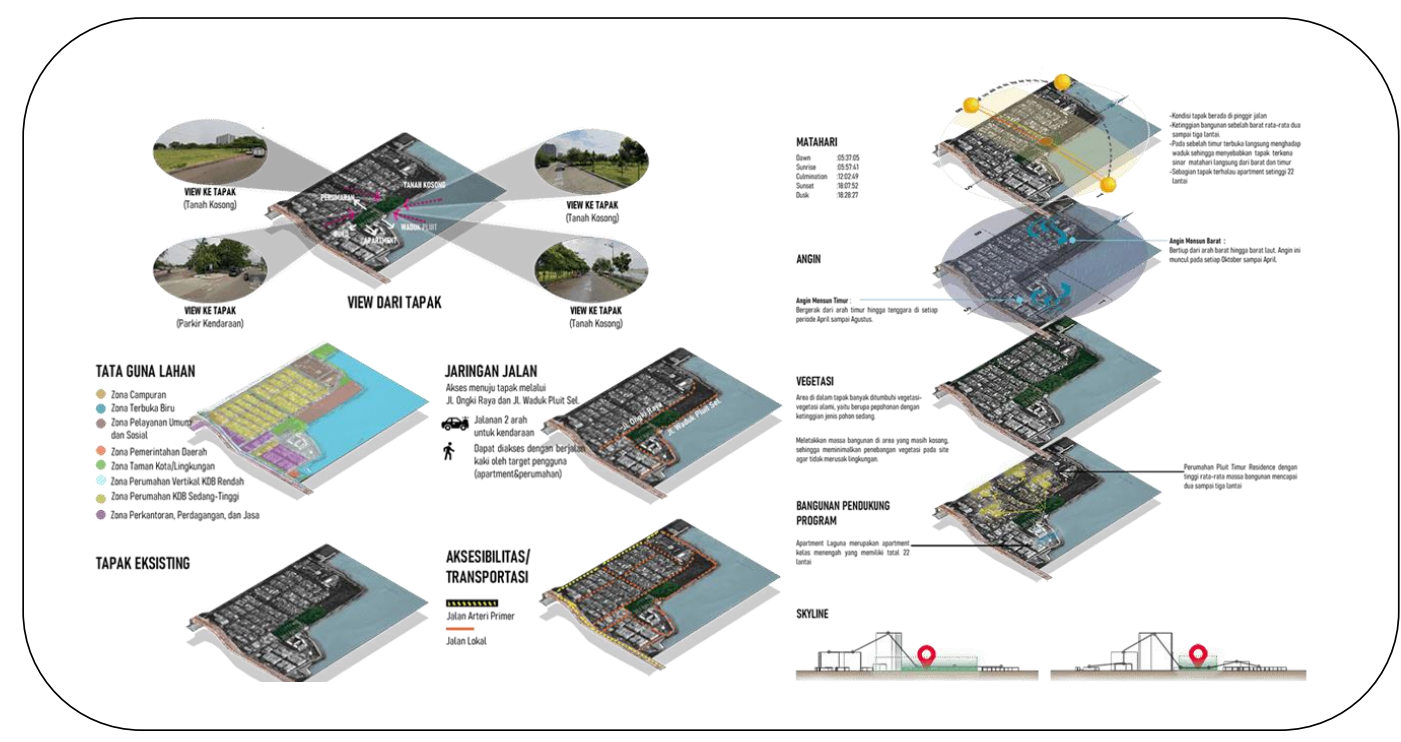

Gambar 3. Analisis Mikro

Sumber: Penulis, 2021

\section{Program dan Pengguna}

Program ruang pada bangunan terdiri dari program lokal dan program yang akan di usulkan. Program lokal merupakan aktivitas yang telah ada pada lokasi dari dulu hingga kini, sementara pada program yang diusulkan merupakan ide program yang akan dikembangkan pada tapak sesuai dengan latar belakang isu.

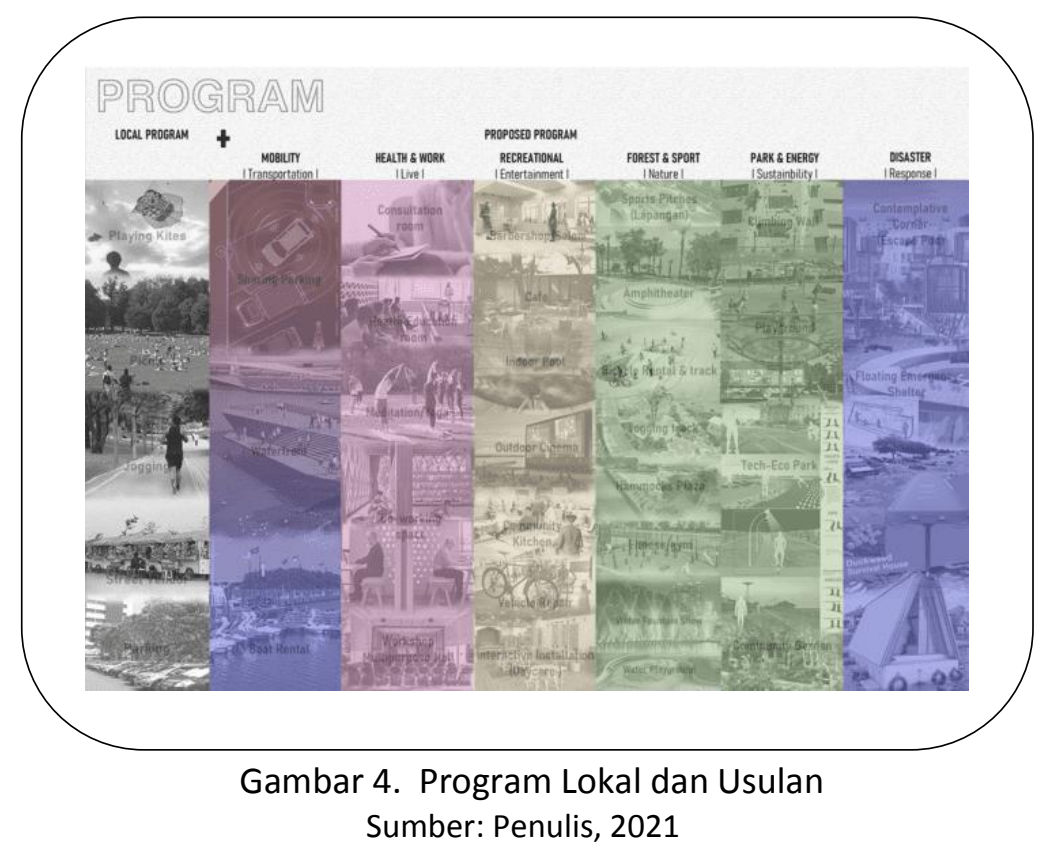

Pengguna program dibagi menjadi dua, yaitu pengunjung dan pengelola. Pengunjung utama atau sasaran dari program ini adalah masyarakat yang tinggal di sekitar tapak, di antaranya adalah keluarga, kelompok anak-anak, remaja, orang tua, pasangan, maupun suatu saat nanti dari kalangan luar. 


\section{Implementasi Metode Pendekatan pada Rancangan Desain Bangunan}

Konsep desain ruang komunal baru menggabungkan beberapa strategi dari hasil analisis data baik tapak maupun data pendukung lainnya dengan desain biofilik. Biofilik memiliki 14 pola desain yang terbagi menjadi tiga aspek, yaitu nature in the space (pola alam dalam ruang), natural analogues (pola analogi alam), dan nature of the space (pola sifat ruang). Berikut ini merupakan tabel kesimpulan secara umum dari penerapan atau implementasi pola biofilik terhadap beberapa aspek desain bangunan.

Tabel 1. Implementasi Pendekatan Biofilik pada Tapak dan Bangunan

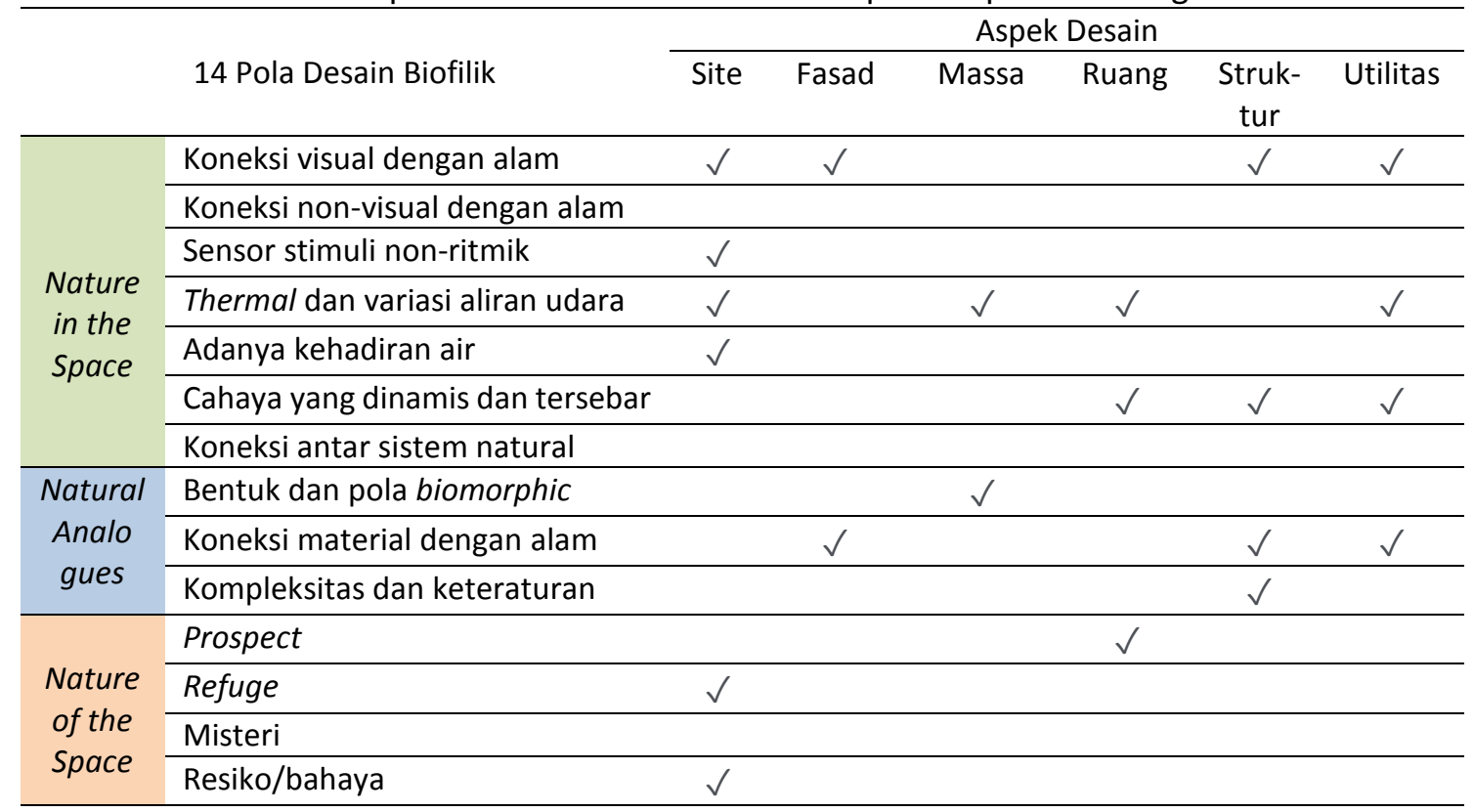

Sumber: Penulis, 2021

\section{Konsep dan Hasil Perancangan}

Site Everydayness

Pluit merupakan daerah rawan banjir karena berada dekat Waduk Pluit, yaitu instalasi perairan dalam pengendalian bajir di Jakarta, mengingat letaknya yang berbatasan langsung dengan Laut Jawa di sisi utara sehingga dalam merancang diperlukan strategi khusus guna meminimalisir dampak yang terjadi pada bangunan saat banjir meluap.

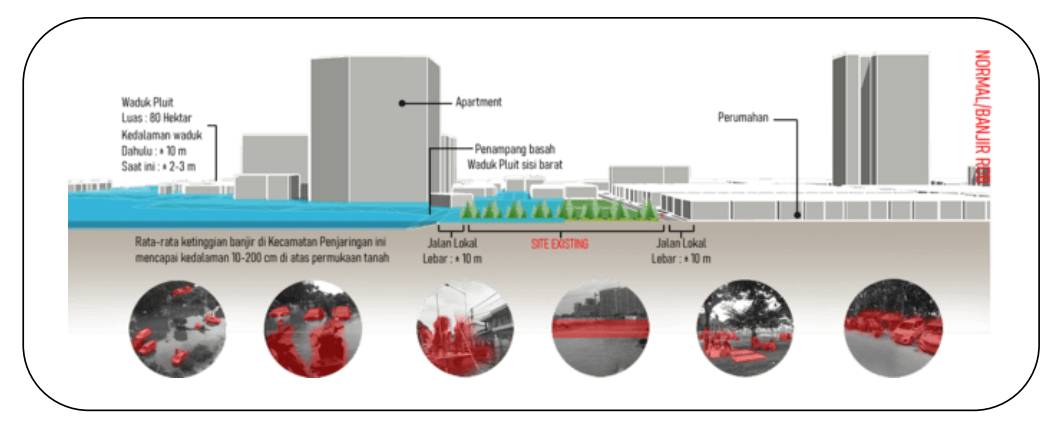

Gambar 5. Site Everydayness

Sumber: Penulis, 2021

Zona hijau adalah milik pemerintah untuk memarkirkan kendaraan. Maka, direncanakan program tambahan guna memperbaiki parkir di lahan tersebut karena terletak di daerah rawan banjir apabila banjir rob datang secara tiba-tiba dengan ketinggian banjir yang lumayan tinggi, kendaraan yang terparkir akan terendam banjir tanpa sempat dipindahkan oleh pemiliknya. 
Sehingga program yang direncanakan merupakan program mixed use dengan usulan awal wellness community + ruang terbuka hijau dan tambahan membangun sharing parking space. Dengan kesimpulan, penukaran zona adalah dengan tujuan untuk merangkul fasilitas yang telah ada di lahan tersebut dengan gambaran seperti gambar di bawah ini.

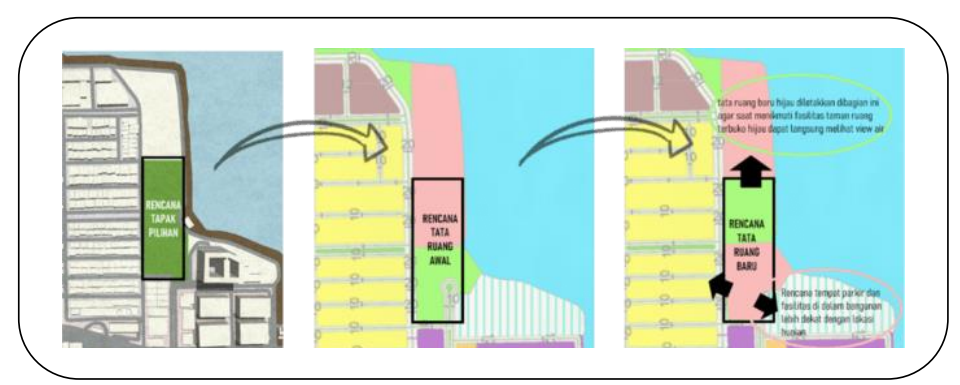

Gambar 6. Argumen Tapak

Sumber: Penulis, 2021

Pengelompokkan Zoning

Zona terbagi menjadi dua, yaitu zona terbangun (Sharing parking/merah, health and work/merah muda, recreation/kuning) dan zona terbuka (Green space/hijau, waduk/ungu).

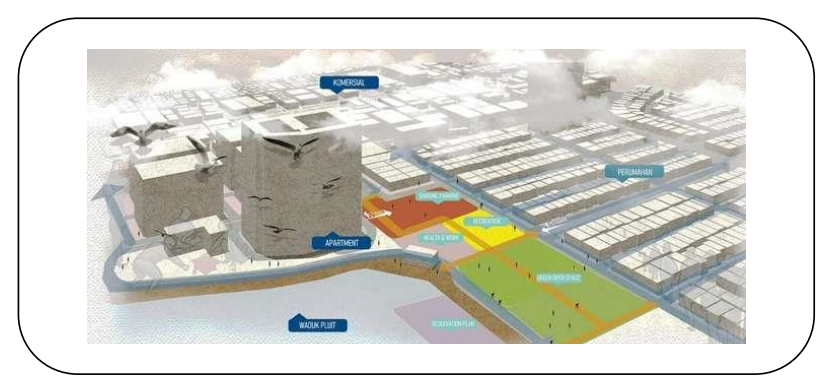

Gambar 7. Penzoningan Tapak

Sumber: Penulis, 2021

Konsep Strategi Desain

Strategi pertama adalah mengatasi stress dengan "The 7 Dimensions of Wellness", di mana kesehatan adalah integrasi penuh dan mengejar pertumbuhan dan keseimbangan yang berkelanjutan. Setiap dimensi berkontribusi pada kesehatan kualitas hidup. Lalu, strategi kedua adalah "Community Stress Issue" untuk membentuk komunitas terhadap bangunan itu sendiri agar desain bangunan dapat digunakan dengan nyaman, aman, dan sehat. Ketiga strategi menghadapi konteks lahan berupa banjir rob, yaitu "Environment (Flood Resilience)" karena banjir bukanlah sesuatu yang dapat kita perbaiki, tetapi kita dapat meminimalisir keadaan terburuk pada bangunan dengan membuat desain yang merespon hal tersebut. Dari ketiga strategi tersebut digabung dan dihubungkan dengan metode yang telah ditentukan saat merancang, yaitu menggunakan metode "Biophilic Architecture".

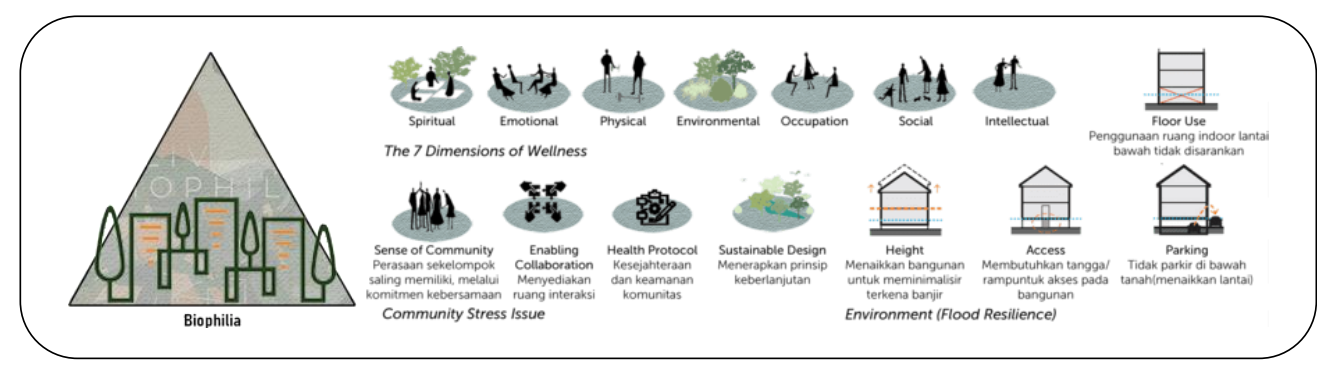

Gambar 8. Konsep Strategi Desain

Sumber: Penulis, 2021 


\section{Konsep Massa Bangunan/Gubahan}

Bagian massa terbangun bangunan akan mewakili program yang diusulkan.

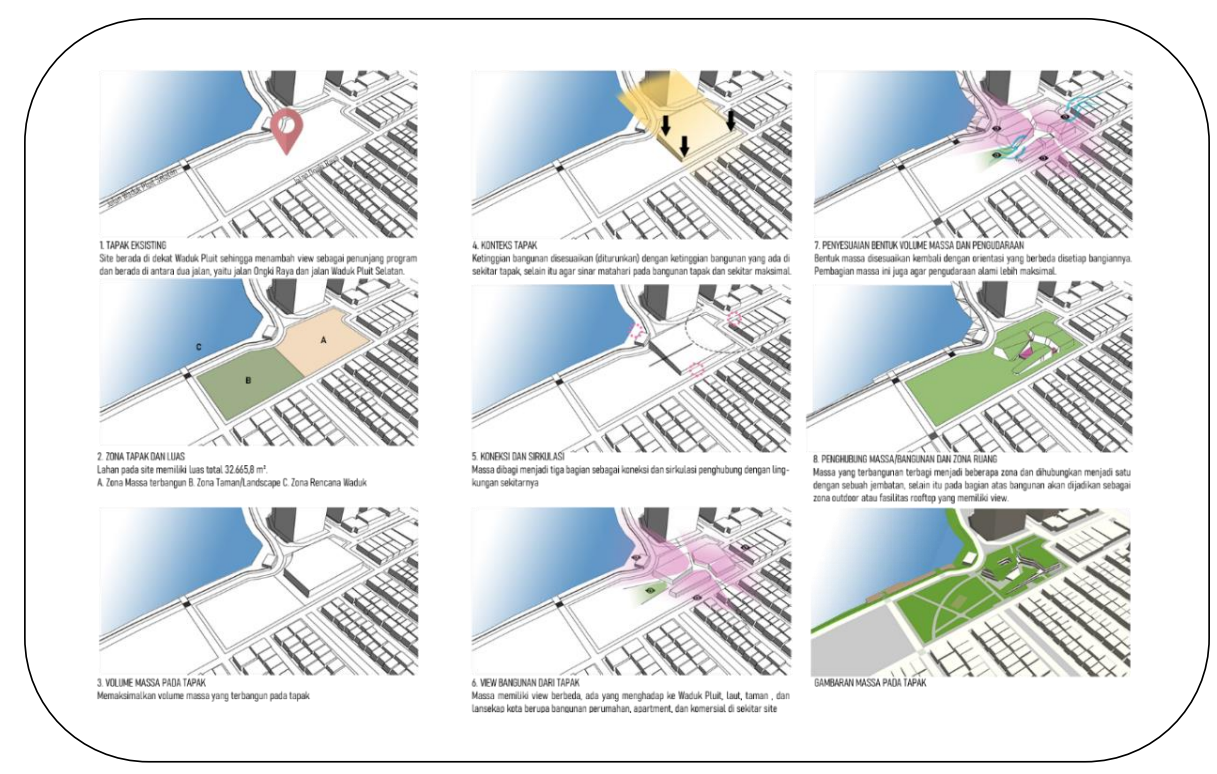

Gambar 9. Transformasi Massa

Sumber: Penulis, 2021

Pencapaian, Sirkulasi, dan Parkir Tapak

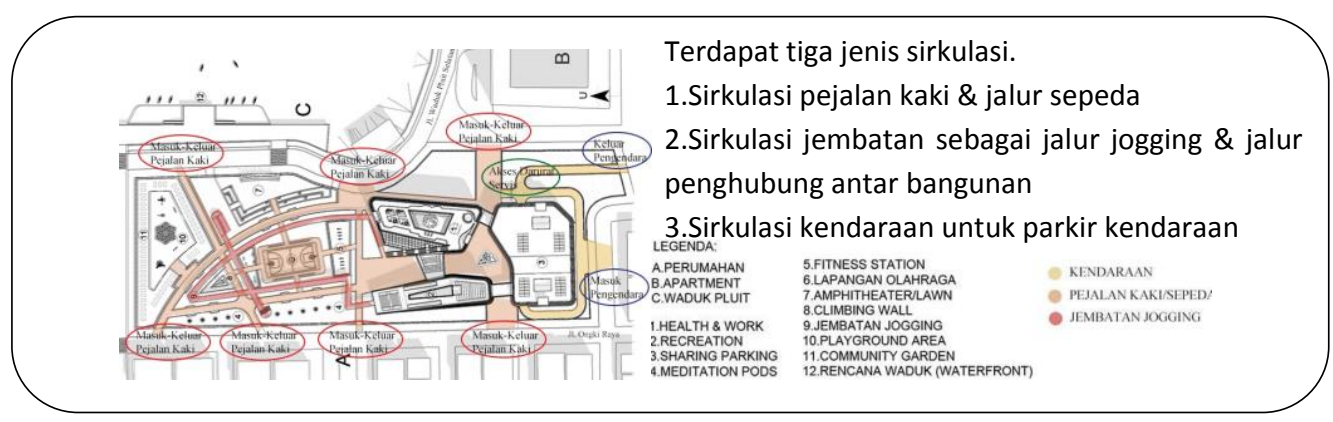

Gambar 10. Blok Plan, Pencapaian, dan Sirkulasi

Sumber: Penulis, 2021

Penerapan Metode dan Strategi ke dalam Konsep Desain

Berikut dijelaskan beberapa penerapan konsep biofilik pada tapak dan bangunan.

a. Rancangan Terhadap Stategi Banjir

Mengacu pada histori, di mana sering terjadi banjir rob akibat dari meluapnya air laut serta waduk, maka bangunan di desain dengan menaikkan satu level lantai. Sisi positifnya adalah ruang paling bawah dapat dijadikan ruang publik sebagai penghubung lingkungan sekitarnya sekaligus menjadi sirkulasi pertukaran udara.

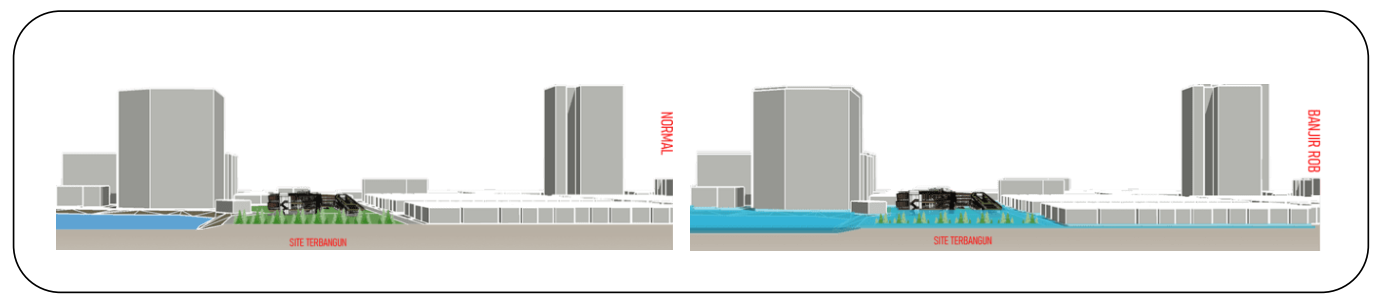

Gambar 11. Penerapan Metode dan Strategi Banjir Sumber: Penulis, 2021 
b. Rancangan Site dan Program

- Koneksi visual dengan alam : Desain landscape dan massa saling terintegrasi dengan lingkungan alam sekitarnya.

- Thermal dan aliran udara : Site jauh dari bising, polusi, dan banyak terdapat pepohonan, serta air sehingga udara cukup sejuk.

- Sensor stimuli non-ritmik : Terdapat banyak pepohonan baik tanaman perdu maupun bunga yang tersebar pada tapak (Rooftop, taman, dan lainnya).

- Refuge : Terdapat meditation pods saat keadaan tidak banjir, namun saat banjir akan dapat digunakan menjadi alat penyelamatan yang berada di taman.

- Risk : Terdapat area bermain panjat dinding dan bungee jumping sebagai salah satu unsur yang dapat mengurangi rasa stress dan meningkatkan adrenalin.

- Kehadiran air : Site memiliki kriteria adanya lingkungan alami, yaitu Waduk Pluit.

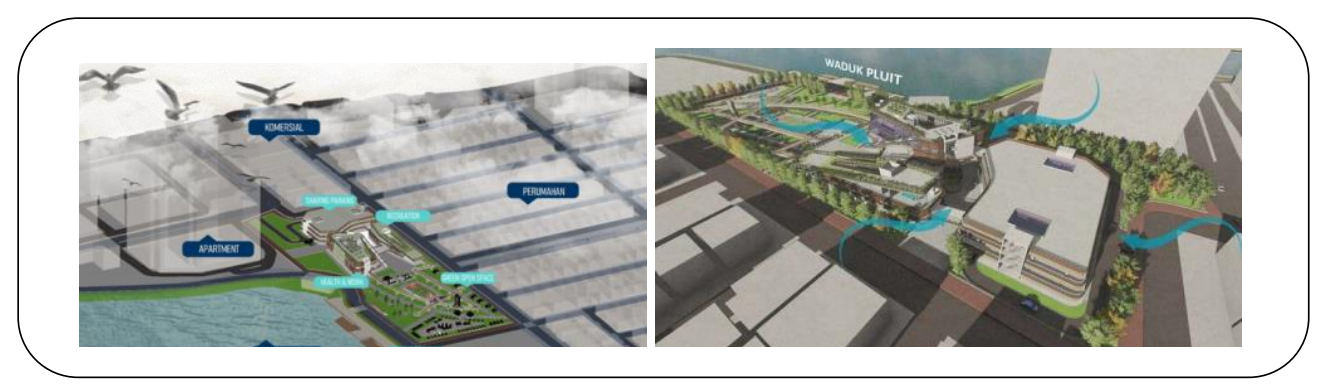

Gambar 12. Penerapan Metode pada Site dan Program

Sumber: Penulis, 2021

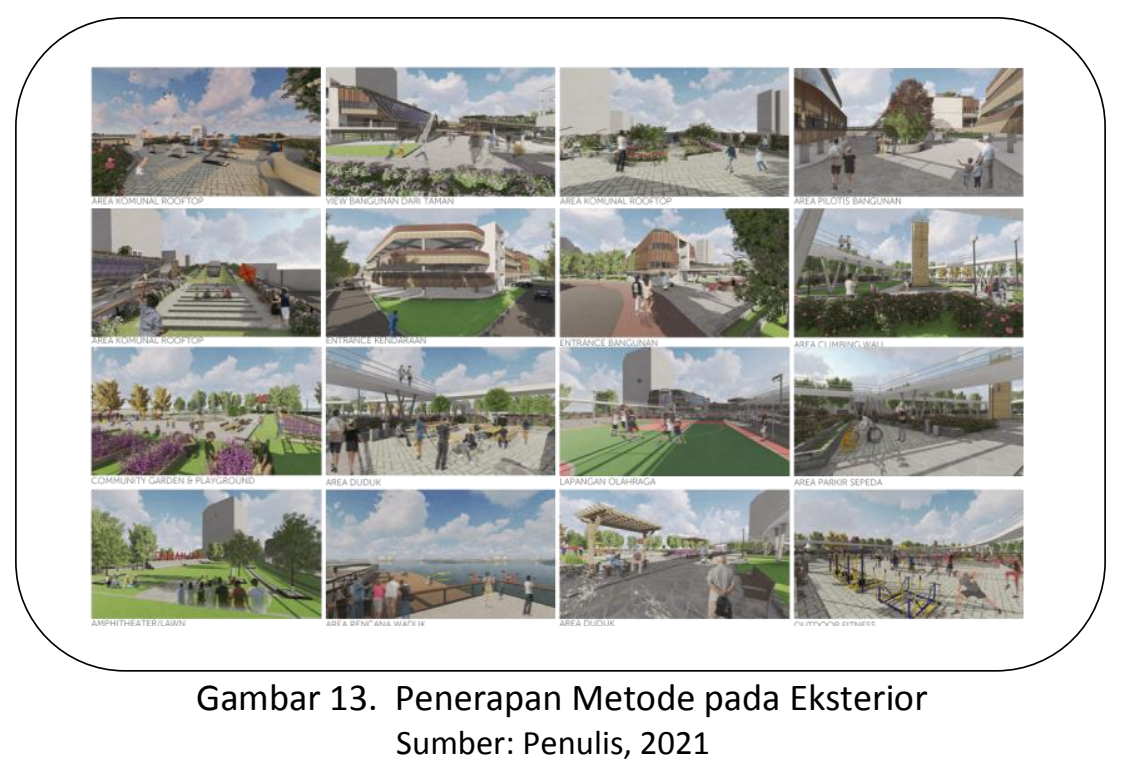

Program pada tapak dan bangunan menerapkan strategi "The 7 Dimensions of Wellness" yang masing-masing terbagi dalam 5 zona berbeda, diantaranya fisik (area olahraga di taman dan kolam renang indoor), emosional (konsultasi pada ahli kesehatan psikologis), intelektual (workshop), spiritual (yoga/meditasi), lingkungan (taman, amphitheater, Waduk Pluit), sosial (community kitchen, community garden, daycare, salon, vehicle workshop, cinema), dan kerja (working space). 


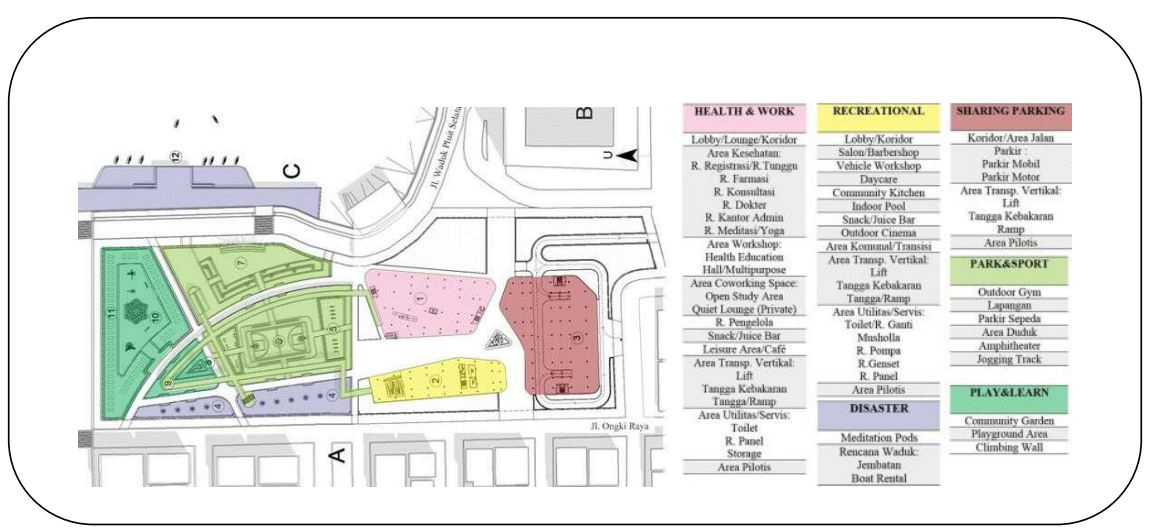

Gambar 14. Site Plan dan Penerapan Konsep Program

Sumber: Penulis, 2021

c. Rancangan Fasad Bangunan

- Koneksi visual dengan alam : Fasad keseluruhan bangunan memberikan bukaan yang cukup banyak walau menggunakan dinding jendela kaca namun, masih dapat dibuka karena menggunakan jendela kaca pivot sehingga tetap terkoneksi dengan unsur elemen alam.

- Koneksi Material dengan alam : Material untuk selubung bangunan menggunakan bahan yang ramah lingkungan (green wall/tanaman rambat, aluminium composite panel).

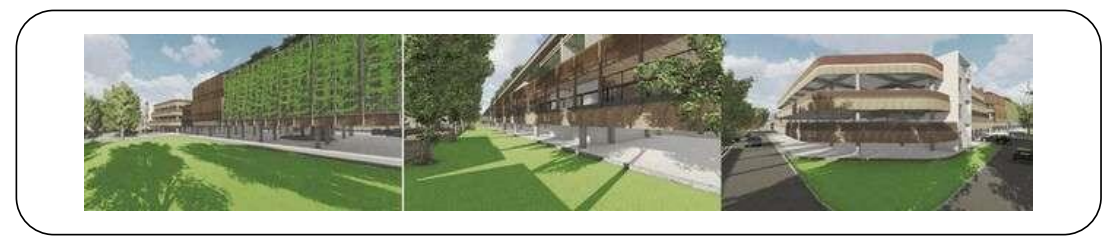

Gambar 15. Penerapan Metode pada Fasad Bangunan Sumber: Penulis, 2021

d. Rancangan Tata Massa

- Bentuk dan pola Biomorphic: Bentuk massa berwujud seperti berundak dan miring.

- Thermal dan variasi aliran udara : Bentuk massa sangat diperhatikan mengikuti konteks tapak agar aliran udara dapat bertukar dengan baik.

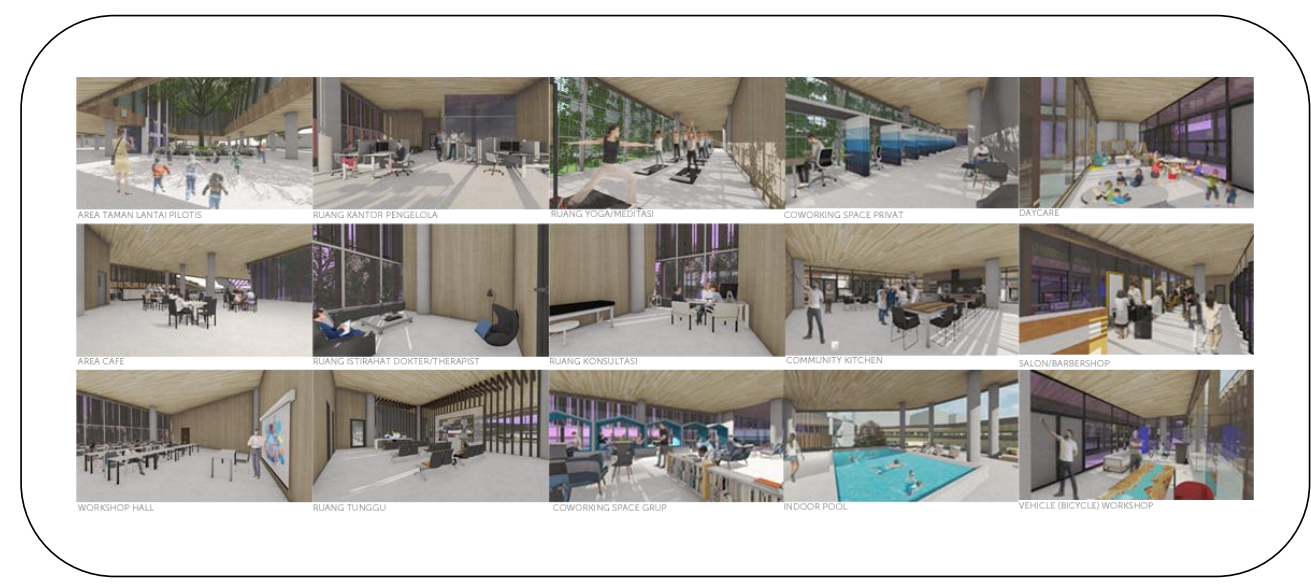

Gambar 16. Penerapan Metode pada Interior Sumber: Penulis, 2021 
e. Rancangan Tata Ruang

- Thermal dan variasi aliran udara : Penghawaan di dalam bangunan menggunakan ac namun dapat juga mengalirkan udara alami dengan membuka kaca jendela.

- Cahaya yang dinamis dan tersebar : Dinding pada bangunan bersifat transparan dan beberapa bersifat terbuka mengakibatkan ruang-ruang di dalam bangunan terpancarkan cahaya alami.

- Prospect : Desain bangunan memiliki bukaan void yang cukup besar sehingga menciptakan pemandangan yang leluasa

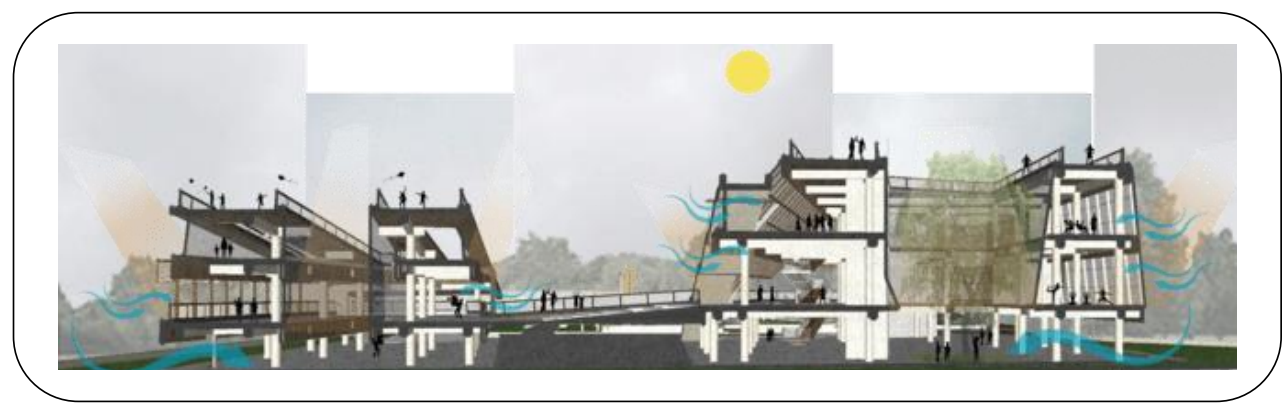

Gambar 17. Potongan Skema Penerapan Konsep Ruang Sumber: Penulis, 2021

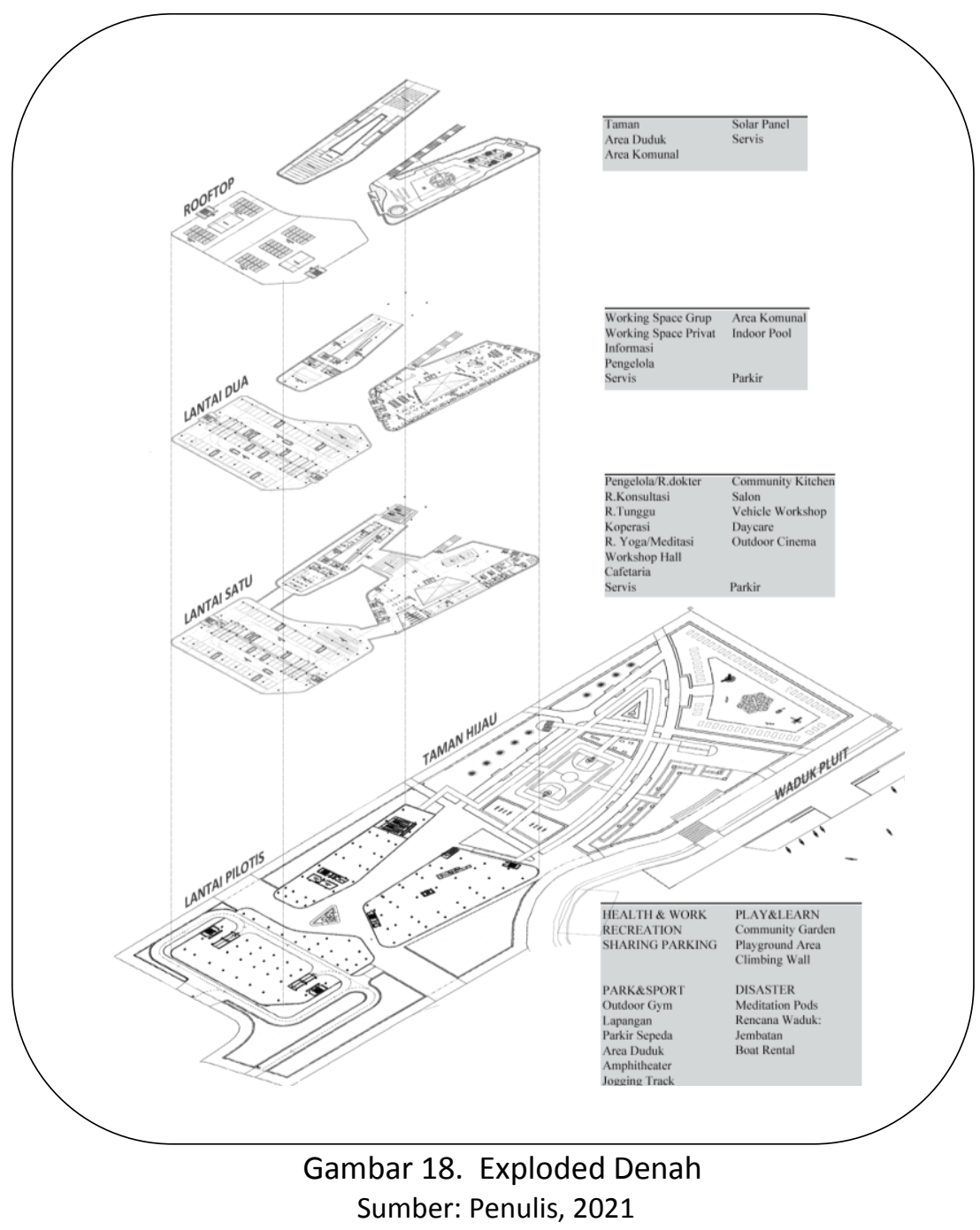


f. Sistem Struktur

- Struktur utama berupa sistem kolom, balok, dan plat lantai. Dimensi kolom berbentuk lingkaran berdiameter $60 \mathrm{~cm}$ dengan pola struktur bentangan mencapai 9 meter. Dimensi balok yang digunakan memiliki lebar $40 \mathrm{~cm}$ dengan tinggi $80 \mathrm{~cm}$. Ketebalan plat lantai, yaitu $20 \mathrm{~cm}$.

- Struktur bagian atap terdiri dari dua jenis, yaitu atap plat lantai dengan struktur beton dan atap greenroof.

g. Sistem Utilitas

- Sistem air bersih dengan downfeed dari PDAM dan GWT yang dipompa ke rooftank.

- Sistem air kotoran disalurkan ke septic tank dan air bekas langsung ke drainase kota.

- Sistem air hujan terdiri dari dua jenis, air hujan dialirkan menuju bak penampungan lalu ke drainase kota dan air hujan dialirkan ke tempat filtrasi ulang di daur ulang.

- Sistem listrik berasal dari PLN dan dilengkapi sistem generator set. Selain itu juga menggunakan teknologi solar panel sebagai sumber daya listriknya.

- Sistem pengudaraan terdiri dari dua jenis, yaitu sistem ac split duct VRV dan sistem pengudaraan alami dengan ventilasi atau jendela kaca pivot.

- Sistem proteksi berasal dari sprinkle dan hydrant box pada titik tertentu.

- Sistem transportasi vertikal terdiri dari lift, tangga darurat, dan ramp.

\section{KESIMPULAN DAN SARAN}

\section{Kesimpulan}

Perancangan Ruang Komunal Baru bertujuan menciptakan program yang dapat digunakan oleh masyarakat sekitar tapak. Tujuan tersebut ditentukan berdasarkan latar belakang isu "Community Stress" akibat pandemi yang mengharuskan menjaga jarak sosial dan melakukan aktivitas di luar rumah menjadi di rumah, contohnya adalah bekerja dan berolahraga sehingga ruang gerak yang kita rasakan pun semakin terasa sempit.

Dari latar belakang tersebut kemudian dirancang rumusan masalah. Pertama, dapatkah arsitektur membantu proses dalam menurunkan tingkat stress? Berdasarkan pembahasan kajian, salah satu cara yang digunakan adalah dengan menerapkan desain yang dapat menjembatani hubungan antara alam natural dengan kesehatan pada psikologis manusia ke dalam sebuah bangunan. Penerapan desain tersebut dapat menggunakan metode biofilik karena menurut sumber yang telah dikaji pada bab sebelumnya, biofilik dapat berpengaruh dan membantu manusia dalam meningkatkan kualitas hidupnya dalam hal psikologis terutama pada masyarakat perkotaan dengan segala kehidupan hiruk pikuknya. Selain itu, desain biofilik dapat menjadi suatu yang berbeda atau keunggulan yang muncul di tengah lingkungan karena memiliki sifat dan pola yang menggabungkan alam dan bangunan sehingga dapat mengurangi rasa stress tersebut.

Pertanyaan selanjutnya, program arsitektur apa yang dapat menjadi wadah kebutuhan suatu kelompok masyarakat sebagai pereda stress? Program arsitektur sendiri yang paling utama adalah memberikan program pada ruang publik yang dekat dan mudah dijangkau dari tempat mereka tinggal dengan dilengkapi fasilitas yang dapat menjadi tempat healing penghilang stress . Fasilitas tersebut antara lain fasilitas sebagai tempat bekerja yang nyaman, fasilitas kesehatan sebagai tempat untuk berkonsultasi pada pihak yang lebih profesional, fasilitas untuk berkomunitas seperti berkebun, memasak, workshop maupun fasilitas yang bersifat rekreasi seperti jogging, berenang, melakukan perawatan diri ke salon, bermain, menonton dan lainnya. Namun hasil desain rancangan tapak dan program ini, penulis menyadari jika hasilnya masih banyak kekurangan terutama dalam penerapan biofilik yang di desain masih kurang maksimal dan mendetail, serta sudut pandang dan hasil presentasi masih perlu dikembangkan dan dipelajari lagi. 


\section{Saran}

Setelah melakukan proses dari awal hingga akhir perancangan, penulis mengharapkan jika ada pendekatan desain lain sebagai metode perancangan dalam menghadapi latar belakang yang sama sehingga dapat menjadi bahan ajar yang berbeda guna menambah wawasan. Lalu, kritik dan saran yang membangun dari berbagai pihak tentunya sangat diharapkan dan dibutuhkan sebagai koreksi dari perancangan ini maupun untuk perancangan selanjutnya. Diharapkan juga laporan tugas akhir yang berjudul Ruiang Komunal baru : Fasilitas Komunitas Untuk Kebugaran, Rekreasi, dan Relaksasi ini dapat diterima sebagai hasil dari penerapan ilmu yang telah didapat selama masa perkuliahan. Akhir kata, penulis mengucapkan terima kasih.

\section{REFERENSI}

Antonioli, M. (2017). What is Ecosophy? Schizoanalysis and Ecosophy: Reading Deleuze and Guattari, 74.

Burnett, S. (n.d.). Biophilic Design + Biomimicry by Shelby Burnett - issuu. https://issuu.com/shelbyburnett/docs/biophilic_design_book_-_shelby_burn

Contamination, E., \& Resiliency, S. (n.d.). COVID-19: Addressing Community Stress and Resilience.

Dias, B. D. (2015). Beyond sustainability-biophilic and regenerative design in architecture. European Scientific Journal, 11(9), 147-158.

Ecosystems, M. E. A., \& Well-Being, H. (2003). A Framework for Assessment. Millennium Ecosystem Assessment. Washington, DC: Island Press.

General Adaptation Syndrome: Your Body's Response to Stress. (n.d.). Retrieved June 29, 2021, from https://www.healthline.com/health/general-adaptation-syndrome

Harsiti. (1992). Pusat Analisis Informasi Ekologi Perkotaan. Perpustakaan Universitas Indonesia.

Stewart, G. T. (1975). Stress in Everyday Life: (a) Stress in Society. Royal Society of Health Journal, 95(2), 65-69.

Heerwagen, J. (2009). Biophilia, health, and well-being. Restorative Commons: Creating Health and Well-Being through Urban Landscapes, 39-57.

Hernández, S. (2010). Eco-architecture III: Harmonisation Between Architecture and Nature (Vol. 128). WIT Press.

Sim, D. (2019). Soft city: building density for everyday life. Island Press.

The 7 Dimensions of Wellness / Mindbody. (n.d.). Retrieved June 30, 2021, from https://www.mindbodyonline.com/business/education/infographic/7-dimensions-wellness

The Mental Health Improvement For Stress-free Environment. (n.d.). Retrieved June 29, 2021, from https://www.smartcity.press/mental-health-improvement/

What is Wellness Lifestyle Real Estate \& Communities? - Global Wellness Institute. (n.d.). Retrieved June 30, 2021, from https://globalwellnessinstitute.org/what-is-wellness/whatis-wellness-lifestyle-real-estate-communities/ 
